\title{
Dissolution of Calcareous Phosphate Rock from Gafsa (Tunisia) Using Dilute Phosphoric Acid Solution
}

\author{
Houda Lefires $^{1}$, Hayet Medini ${ }^{2}$, Adel Megriche ${ }^{1}$, Arbi Mgaidi ${ }^{2 *}$ \\ ${ }^{1}$ Industrial and Chemical Laboratory, Faculty of Sciences, University El Manar Campus, Tunis, Tunisia \\ ${ }^{2}$ Chemistry Department, Faculty of Sciences \& Art Al Ula, Taibah University, Medina, KSA \\ Email: ${ }^{*}$ arbi.mgaidi@fst.rnu.tn, ${ }^{*}$ amgaidi@taibahu.edu.sa
}

Received October 16, 2013; revised November 16, 2013; accepted November 22, 2013

Copyright (c) 2014 Houda Lefires et al. This is an open access article distributed under the Creative Commons Attribution License, which permits unrestricted use, distribution, and reproduction in any medium, provided the original work is properly cited. In accordance of the Creative Commons Attribution License all Copyrights @ 2014 are reserved for SCIRP and the owner of the intellectual property Houda Lefires et al. All Copyright (C) 2014 are guarded by law and by SCIRP as a guardian.

\section{ABSTRACT}

In the present study, porous structure of raw and calcined phosphate ore particles was examined. The specific surface area and the pore volume were determined by nitrogen adsorption. Raw particles and calcined ores were leached using dilute phosphoric acid solution $\left(4 \% \mathrm{P}_{2} \mathrm{O}_{5}\right)$. In all cases, the ESEM (Environmental Scanning Electron Microscopy) observations show that the grain of phosphate holds its shape ovoidale. The sample heated at $780^{\circ} \mathrm{C}$ presented the lowest specific surface area $0.6 \mathrm{~m}^{2} / \mathrm{g}$ at each reaction time, and the unreacted phases were analysed using XRD, FT-IR, Nitrogen adsorption and ESEM observations. The selective leaching curves were evaluated in order to test the validity of kinetics models. A mathematical model in the following form was applied: $\left(-\ln (1-\alpha)=k t^{m}\right)$. The dissolution of the two samples (raw and calcined phosphate) has been observed to take place in two steps: the first being fast and the second being slow.

\section{KEYWORDS}

Phosphate Rock; Dissolution; Phosphoric Acid; Porosity Evolution; Dissolution Kinetics

\section{Introduction}

Phosphate rocks are complex raw materials and are mainly used in the manufacture of phosphate fertilizers. The composition of this rock varied from ore deposit to another and cannot be used directly as fertilizers because of their solubility in humid soil.

To be utilized by plants, phosphorus must first be dissolved in various acids (phosphoric, nitric, sulfuric, mixture phosphoric/sulfuric). Sardisco et al. [1] investigated the digestion of low-grade phosphate ores using phosphoric acid.

Several studies [2-8], have shown that the calcium carbonate content of phosphate rocks can be reduced by calcinations or by acid leaching Ben Brahim et al. [9] this can affect the particle's texture.

According to Sengul et al. [6], calcinations may lead to almost complete disposal of carbonates present in the phosphate rock.

\footnotetext{
"Corresponding author.
}

Mgaidi et al. [10] concluded that the morphology of phosphate particles after different calcinations treatments are not affected but up to $780^{\circ} \mathrm{C}$ the microstructure was close to that of pure Fap.

Ben Brahim [11] showed that the specific surface area of a raw phosphate rock decreases and then increases with the reaction time in diluted phosphoric $(0.2 \mathrm{M})$, while the conversion rate increases continuously.

Zafar et al. [7] concluded that the change in the reaction rate constant of leaching of calcareous phosphate rock in dilute phosphoric acid can be attributed to the porous matrix of the rock particles. However, no experimental phosphate was given.

Blazy and Jdid [12] noted that the flash calcinations enable to removal of $57.5 \%$ of the total $\mathrm{CO}_{2}$, while the apatitic $\mathrm{CO}_{2}$ is less affected.

According to Gharabaghi et al. [13], the calcinations decrease the reactivity of phosphate rock during phosphoric acid production and change the surface proprieties of phosphate mineral. 
A number of studies for the kinetic model describing the selective acid leaching of phosphate rock and analyzing kinetic data were found in literature [4,5,7,13-16].

The aim of this work is to understand and compare the structural changes due to the combined effects of calcinations and reaction time of acid leaching.

Furthermore, this investigation is focused on the application of an kinetic heterogeneous model to fit experimental data.

\section{Materials and Experimental}

\subsection{Materials}

\section{Samples Preparation}

Phosphates rocks were obtained from a mine located at Gafsa (southern of Tunisia).

It was supplied by the manufacture CPG (Company of Phosphate from Gafsa).

The rock samples were crushed and sieved to collect various site fractions.

The desired site fraction $(250 \mu \mathrm{m})$ was dried in an electric oven at about $105^{\circ} \mathrm{C}$ cooled to room temperature and stored in closed desiccators.

A known amount of this fraction was heated at $780^{\circ} \mathrm{C}$ for 1 hour. This sample will be noted in the text (PC). The unheated ore, to compare the effects of acid leaching, will be noted (PN).

For the selection of an acid, the following important factors were taken into considerations.

1) Selected acid should be cheaper and easily recovered like phosphoric acid present in the plant.

2) Dilute acid will be less destructive and products must be collected separately. For example $\mathrm{H}_{2} \mathrm{SO}_{4}$ is not suitable to avoid the gypsum precipitation at the particle surface.

3) The reaction time of the leaching process will be relatively small (30 to $50 \mathrm{~min}$ ).

In this work, one term of the above factors dilute phosphoric acid was selected for the leaching process.

Chemical pure phosphoric acid (85 wt\% $\mathrm{H}_{3} \mathrm{PO}_{4}$ ) and distilled water were used to prepare the solution containing $4 \mathrm{wt} \% \mathrm{P}_{2} \mathrm{O}_{5}\left(1 \mathrm{~mol} \cdot \mathrm{L}^{-1}\right)$.

\subsection{Experimental Procedure}

The dissolution process was carried out in a reactor with dual envelope of a capacity of $150 \mathrm{ml}$. A magnetic stirrer was used to stir the reactor contents, and a thermostat was employed to maintain the reaction medium at a given temperature. At the beginning, $100 \mathrm{ml}$ of the phosphoric solution $\left(1 \mathrm{~mol} \cdot \mathrm{L}^{-1}\right)$ was put into the reactor, and after it reached the desired temperature, $10 \mathrm{~g}$ of the ore sample (PC or PN) was added to the system. The solid/ liquid ratio is equal to $1 / 10$ (mass/Volume) and the temperature $\left(25^{\circ} \mathrm{C}\right)$ were fixed for all the experiments. The reaction time was varied between 1 and $60 \mathrm{~min}$.

At the end of each experiment, the stirring was stopped, the reactor was placed rapidly in a bath of ice, to stop the reaction, and all of the reactor contents were then filtered off. The solid remaining was washed, dried during 12 hours at $105^{\circ} \mathrm{C}$ then weighed with a precision.

The remaining solids and the sample $\mathrm{PC}$ and $\mathrm{PN}$ were characterized by diffraction of X-ray diffraction (XRD), infrared spectroscopy (FT-IR), BET method and examined by Environmental Scanning Electron Microscopy (ESEM).

\section{Results and Discussions}

\subsection{Physico-Chemical Characterizations of the Phosphate Samples before Dissolution}

The X-ray diffractograms of PC and PN were obtained with a Philips diffractometer using the $\mathrm{CuK}_{\alpha}$ radiation produced at $32 \mathrm{kV}$ and $20 \mathrm{~mA}$ by a Philips PW $1043 \mathrm{X}$ ray tube.

As seen in Figure 1, peaks characteristic of carbonate apatite, fluorapatite Fap and calcite are present and persist even after calcinations at $780^{\circ} \mathrm{C}$ during 1 hour.

According to the Ben Brahim et al. (1999) [11], the calcination lead to a phosphate with relatively higher $\mathrm{P}_{2} \mathrm{O}_{5}$ and $\mathrm{CaO}$ contents and a low $\mathrm{CO}_{2}$.

The two Samples (PC and PN) were further investigated by infrared (IR) spectrometry analysis on PERKIN ElMER apparatus using $\mathrm{KBr}$ pastilles technique. A scanning rate of $40 \mathrm{~cm}^{-1}$ per minute was employed.

Spectrums were recorded and bands were assigned (see Figure 2). Peaks observed at 564, 608, 960 and $1063 \mathrm{~cm}^{-1}$ were assigned to $\mathrm{PO}_{4}^{3-}$ groups. The characteristic vibration bands of $\mathrm{CO}$ apatitic carbonate are located to 864, 1435 and $1470 \mathrm{~cm}^{-1}$. This assignment agrees with the Brassens [17] and Szilas [18] results. The bands relating to the carbonates ions observed at 864 ,

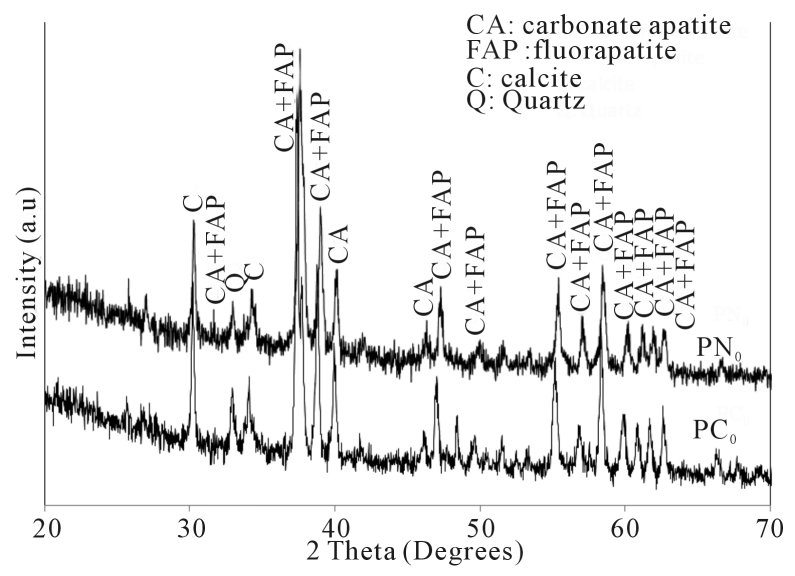

Figure 1. X-ray powder diffractograms of two phosphate samples: PN raw material, $P C$ calcined at $780^{\circ} \mathrm{C}$. 
1435 and $1470 \mathrm{~cm}^{-1}$ were inexistent in the XRD patterns of the igneous phosphate from Kola can be it seen from Figure 2.

The particles size distribution of the two samples was determined with a MALYERN laser master sizer hydro 2000. The grains were placed in a water suspension. The mean size of $216 \mu \mathrm{m}$ was obtained and as it can be seen from Figure 3, the volume particle diameter distribution was narrow and monomodal.

The surface characteristic and elementary composition of the two samples (PC and PN) were studied using Environmental Scanning Electron Microscopy. As illustrated in Figure 4, the shape of phosphate particles is not affected after heating at $780^{\circ} \mathrm{C}$ during 1 hour but PN particles seem more pitted and more porous. Microanalysis revealed the same elementary composition (P, Ca and O) for the two samples.

Furthermore, no distinguishing parts, the dark gray ore attributed to $\mathrm{CaCO}_{3}$, were observed in our samples, contrarily to Turkey phosphate particles (Sengul et al.) [6].

According to Mgaidi et al. [10], calcination affects the nitrogen isotherm adsorption/desorption of the phosphate grains.

The porosimetric parameters of the two samples (PC and $\mathrm{PN}$ ) were obtained from the analysis of the adsorption/desorption isotherm of $\mathrm{N}_{2}$ at $77 \mathrm{~K}$.

Using the BET method, the PC sample exhibit an $\mathrm{S}_{\mathrm{BET}}$ equal to $0.6 \mathrm{~m}^{2} / \mathrm{g}$ however the $\mathrm{PN}$ have an $\mathrm{S}_{\mathrm{BET}}$ equal to $16 \mathrm{~m}^{2} / \mathrm{g}$.

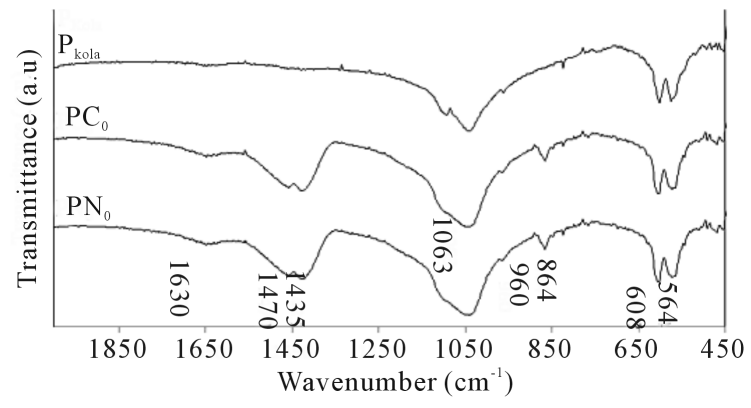

Figure 2. Infrared absorption spectra of three samples PN, PC and igneous phosphate (Kola).

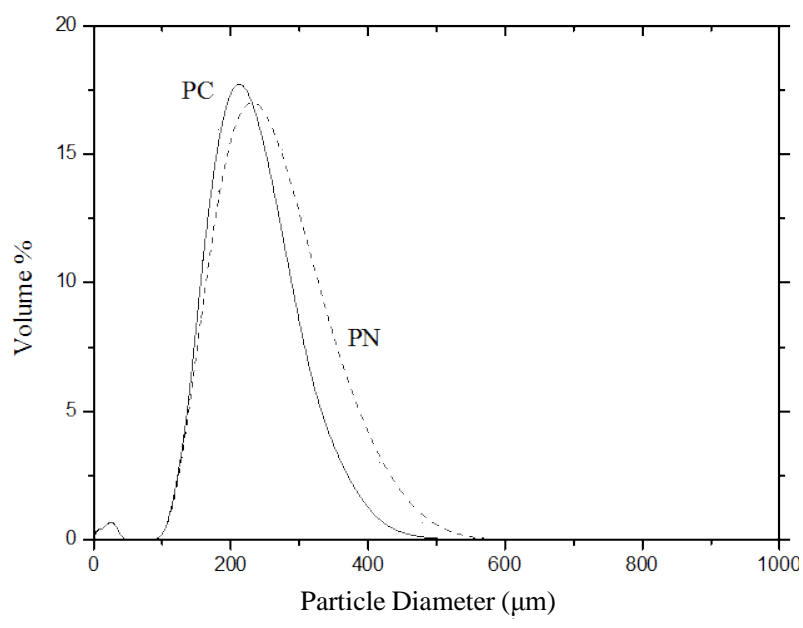

Figure 3. Voluminal granulometric distribution.

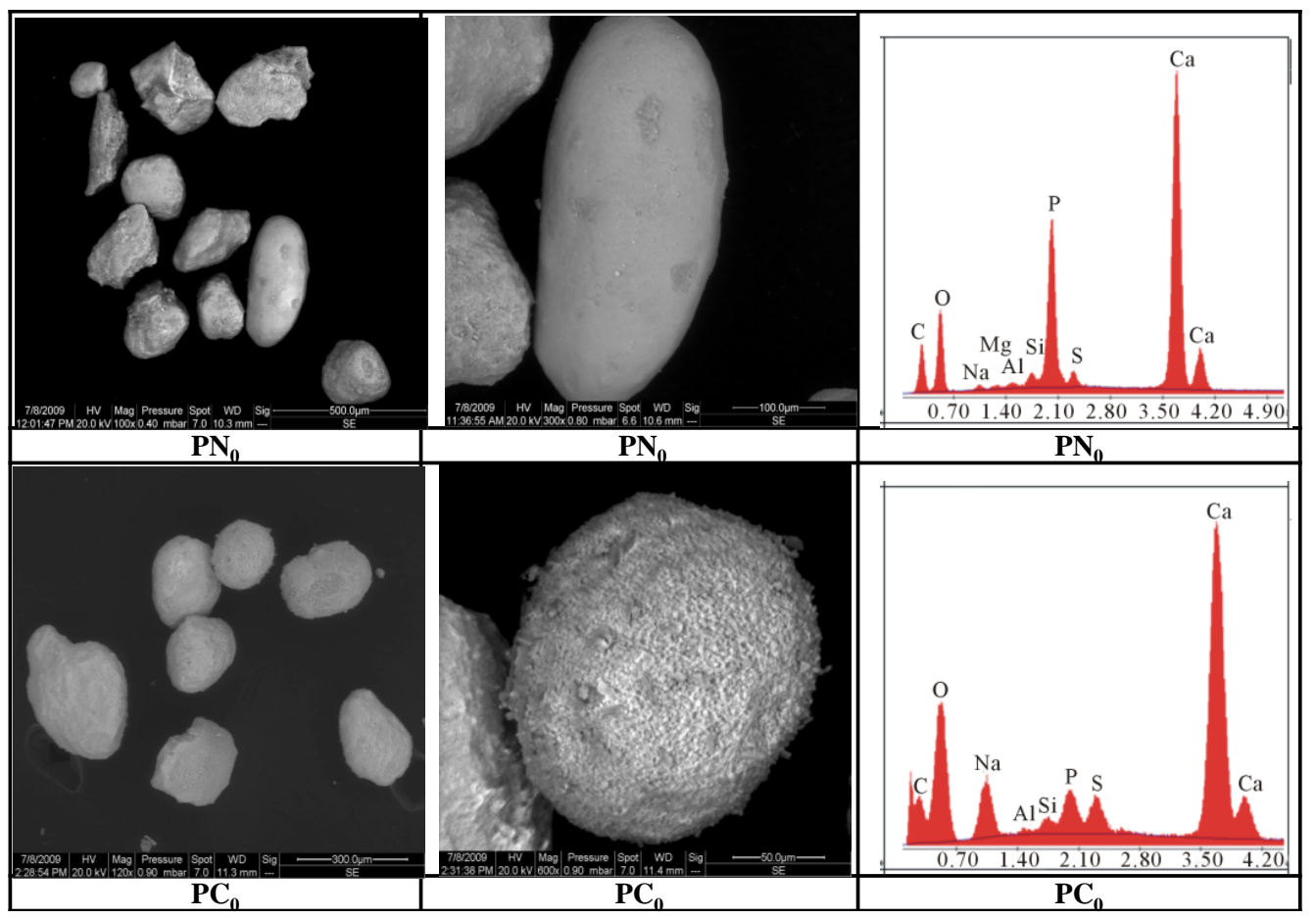

Figure 4. ESEM, Micrographs of phosphate samples: PN (raw sample), PC (calcined at $780^{\circ} \mathrm{C}$ ) and PN (a), PC (a) represents: the qualitative chemical composition. 
As it can be seen from Figure 5, for the heated sample at $780^{\circ} \mathrm{C}(\mathrm{PC})$ the hysteresis phenomenon was absent but the PN sample indicate an hysteresis loop corresponding to $\mathrm{H}_{3}$ type (according to the WPAC classification) with indicates the presence of the ink-bottle shaped mesopores.

\subsection{Effect of Reaction Time on the Texture of Reaming Solids}

The XRD patterns of the reaming solids after 2, 10 and 30 min of acid leaching of the PC samples were illustrated in Figure 6. From this figure, we can conclude that all peaks characteristic of phosphate rocks still present. Also, peaks characteristic of calcite the mineralogical composition of the particles does not change significantly. According to Gharabaghi et al. [13], the time required for carbonate dissolution depends on the particles size and the nature of the adherent materials existing in the phosphate rocks, but this conclusion is not consistent with the IR analysis. As it can be seen from Figure 7, peaks assigned to PO groups, remained at the same position (564, 608, 960 and $1063 \mathrm{~cm}^{-1}$ ). However, a very marked reduction in the $\mathrm{CO}$ vibration band at $864 \mathrm{~cm}^{-1}$ was observed. The well defined doublet at 1435 and $1470 \mathrm{~cm}^{-1}$ assigned to $\mathrm{CO}$ vibration was also affected by acid leaching.

The change of texture of calcined phosphate accompanying acid leaching was revealed by nitrogen adsorption.

As shown by the curves plotted in Figure 8, an appearance of a hysteresis loop after 2 min of leaching. This is can be attributed to the widening of mesopores. This is confirmed by the results given in Figure 9, the $\mathrm{S}_{\mathrm{BET}}$ increase reaching the value of $10.5 \mathrm{~m}^{2} / \mathrm{g}$ after $3 \mathrm{O}$

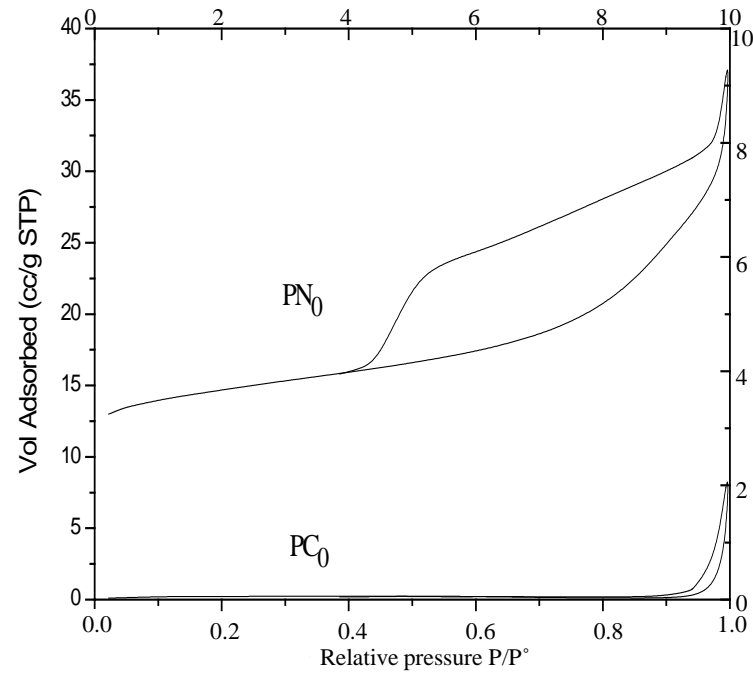

Figure 5. Isotherm adsorption-desorption of $\mathbf{N}_{2}$ relating to PN and PC.

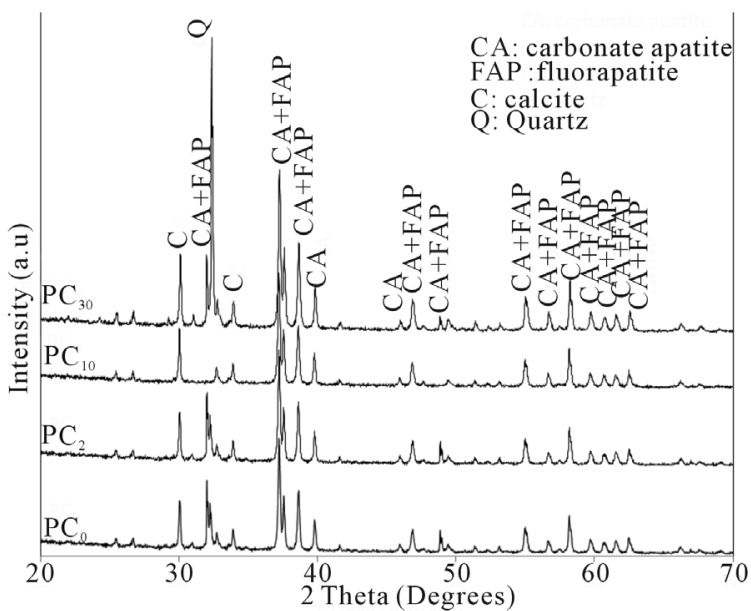

Figure 6. Diffractograms of $x$-rays of solid residues of a PC after various apparent times of reaction.

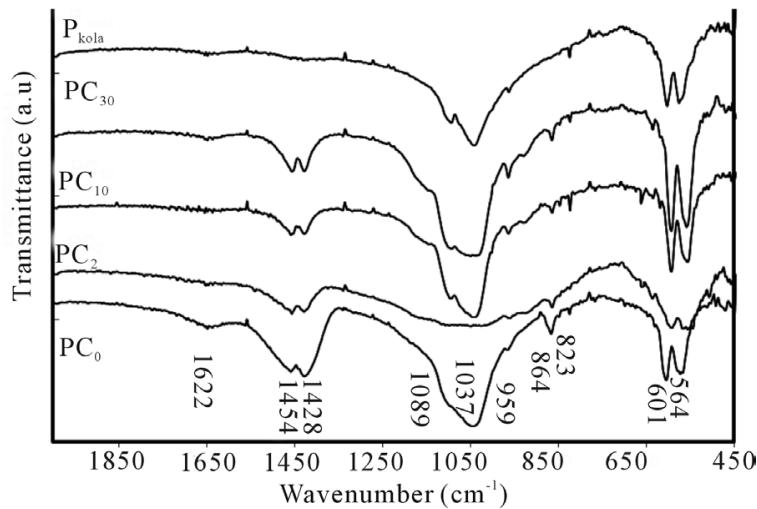

Figure 7. Infrared spectra of the absorption of residues of acid dissolution of a PC after various apparent times of reaction.

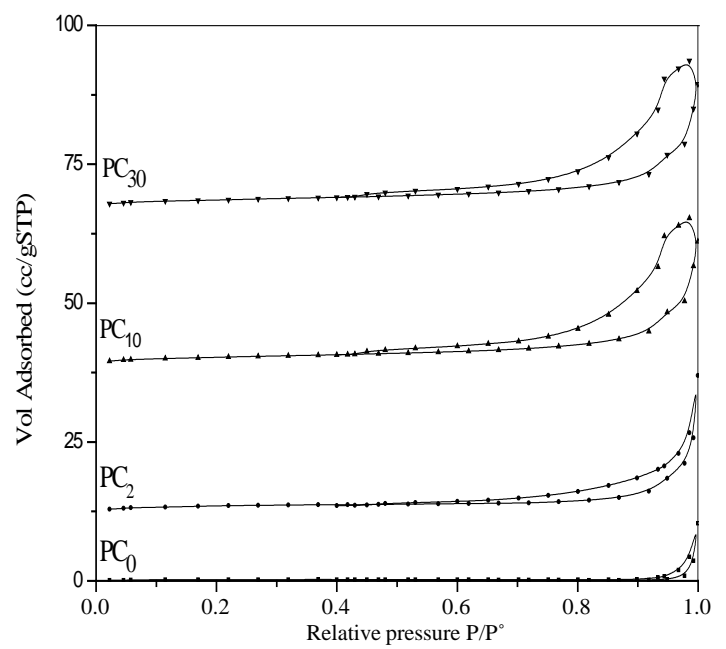

Figure 8. Adsorption-desorption isotherms of $\mathrm{N}_{2}$ relative for phosphate calcined during 2, 10 and $30 \mathrm{~min}$.

min of leaching.

The evolution of specific surface area can be ascribed 
to the sponge like texture of grain after acid leaching and somehow to the disintegration of the aggregates as revealed by the ESEM photomicrograph reported in Figure 10.

\section{Variation of Conversion Rate $(\alpha)$ as Function of the Time}

The reaction of the conversion rate $(\alpha)$, expressed in \% of weight:

$$
\alpha=\frac{\left(m_{0}-m\right) \cdot 100}{m_{0}}
$$

where $m_{0}$ is the initially introduced mass equals $10 \mathrm{~g}$ and $\mathrm{m}$ the remaining mass after a time $\mathrm{t}$ of reaction.

Where carbonate apatite is added into dilute phosphorric acid, the reaction taking place can be written as

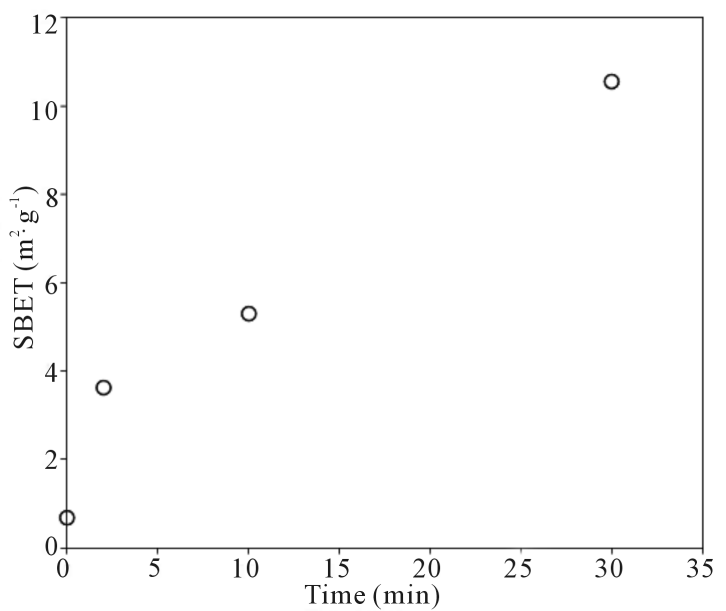

Figure 9. Variation of the BET surface of PC as a function of time of reaction

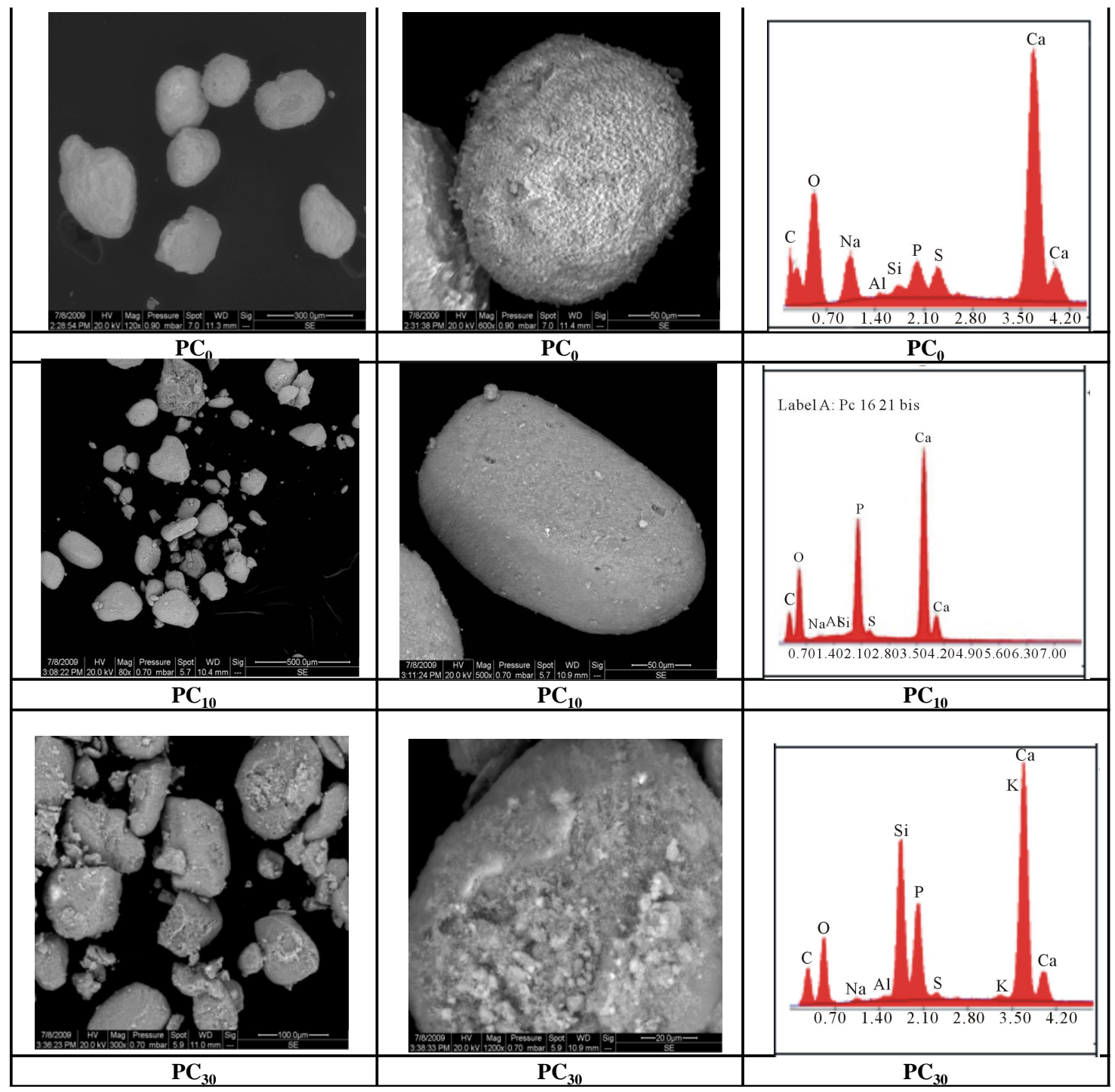

Figure 10. ESEM, Micrographs of phosphate samples $\mathrm{PC}_{0}$ phosphate calcined at $780^{\circ} \mathrm{C}, \mathrm{PC}_{10}$ leached for 10 min, $P C_{30}$ leached for $30 \mathrm{~min}$, and the qualitative chemical composition. 
flows:

$$
\begin{aligned}
& \mathrm{CaCO}_{3} \cdot 3 \mathrm{Ca}_{3}\left(\mathrm{PO}_{4}\right)_{2(\mathrm{~s})}+14 \mathrm{H}^{+} \\
& \leftrightarrow 10 \mathrm{Ca}^{2+}+6 \mathrm{H}_{2} \mathrm{PO}_{4}^{-}+\mathrm{CO}_{2}+\mathrm{H}_{2} \mathrm{O}
\end{aligned}
$$

If we assume that the calcite can be dissolved in such medium like apatite, a second reaction can be written:

$$
\mathrm{CaCO}_{3}+2 \mathrm{H}_{3} \mathrm{PO}_{4} \leftrightarrow \mathrm{Ca}^{2+}+2 \mathrm{H}_{2} \mathrm{PO}_{4}^{-}+\mathrm{CO}_{2}+\mathrm{H}_{2} \mathrm{O}
$$

Figure 11, present the results from leaching tests under different reaction times at room temperature using the two samples (PC and PN). In all cases, with increasing of reaction time, the extent of dissolution $(\alpha)$ increases. After 10 min of reaction time, the extent of dissolution remains constant equal to $38 \%$ for the PC sample and $52 \%$ for the PN ore.

According to earlier studies, Mgaidi et al. [10], the reaction rate is controlled by the diffusion of $\mathrm{Ca}^{2+}$ from the solid surface through the solution boundary layer.

According to Abali et al. [15], Huffmann et al. [14] and Yartazi et al. [16], it seems that the reaction rate does fit a pseudo homogenous first order reaction model in following form:

$$
-\ln (1-\alpha)=k t^{m}
$$

where $m$ and $k$ are constants.

Figure 12, present the representation of $\ln (-\ln \ln (1-\infty))=f(\ln \ln (t))$. As it can be clearly see from this figure that the dissolution process took place in two steps. The first step was being attributed to freely available calcite material and/or spaces on the phosphate particle. The second step may be representing the dissolution of the apatite matrix.

The regression coefficients $R$ and the parameters $K$ and $m$ were calculated using the solver software. Values of $R, k$ and $m$ are grouped in Table 1 .

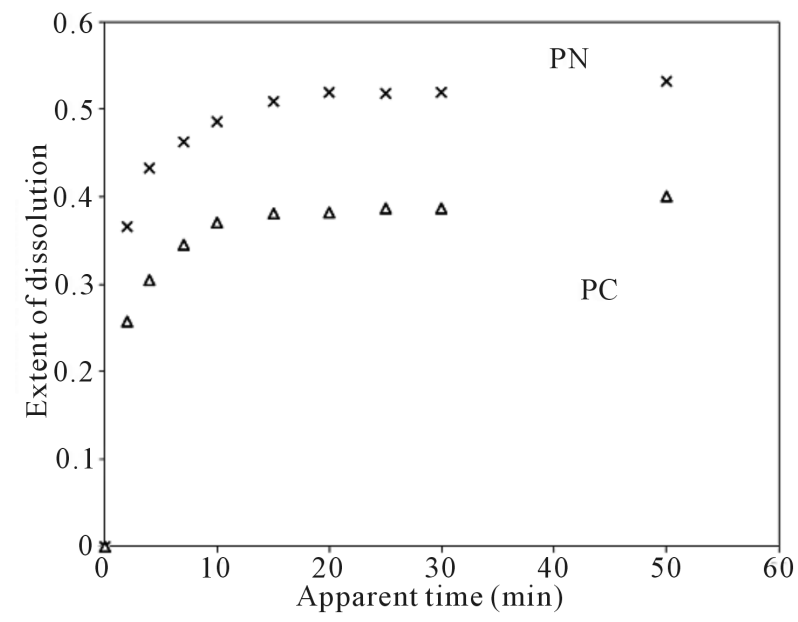

Figure 11. Extent of dissolution (mass\%) according to the apparent time of reaction.

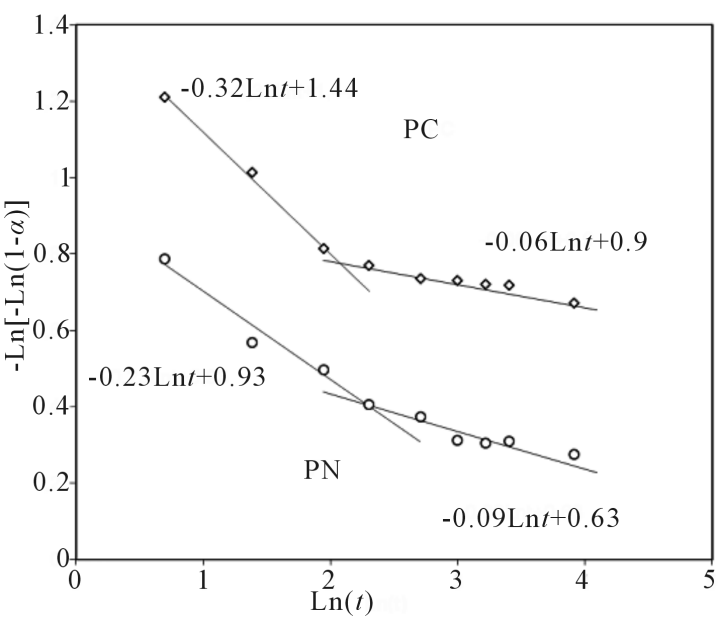

Figure 12. Curve $-\ln [-\ln (1-\alpha)]=f(\ln (t))$ for the raw phosphate and the calcined phosphate.

Table 1. Pseudo homogenous first-order reaction kinetics models.

\begin{tabular}{cccc}
\hline $\begin{array}{c}\text { Phosphate } \\
\text { samples }\end{array}$ & Step & Kinetic model & $\begin{array}{c}\text { Correction. } \\
\text { Coefficient }\end{array}$ \\
\hline \multirow{2}{*}{ PC } & 1 st (fast) & $-\ln (1-\alpha)=0.23 t^{0.32}$ & 0.996 \\
& $2^{\text {nd }}$ (slow) & $-\ln (1-\alpha)=0.40 t^{0.6}$ & 0.987 \\
PN & 1 st (fast) & $-\ln (1-\alpha)=0.39 t^{0.23}$ & 0.998 \\
& $2^{\text {nd }}$ (slow) & $-\ln (1-\alpha)=0.53 t^{0.09}$ & 0.988 \\
\hline
\end{tabular}

\section{Conclusions}

The evolution of texture of heated phosphate sample as function of acid leaching reaction time was investigated.

The results indicate that the specific surface area and the isotherm adsorption/desorption of the solids are affected by the acid leaching time. However, the mineralogical composition is not affected.

At the beginning, the sample (phosphate heated at $780^{\circ} \mathrm{C}$ during 1 hour) is nonporous materiel and after acid leaching the solid presents a mesoporosity.

The kinetics of this leaching process were investigated in terms of extent of dissolution evolution. It seems that the reaction rate does fit a pseudo homogenous first order reaction model.

\section{REFERENCES}

[1] J. B. Sardisco, D. E. Holcomb and E. K. Drechsel, "Phosphoric Acid and Additional Products from Phosphate Ore," US Patent, Vol. 4, No. 479, 1984, p. 923.

[2] T. Gunduz and B. Gumgum, "The Enrichment of LowGrade Mazidagi Phosphates by Calcination and Extraction Methods," Separation Science and Technology, Vol. 22, No. 6, 1987, pp. 1645-1648.

[3] S. I. Abu-Eishah, I. S. El-Jallad, M. Muthaker, M. Tou- 
qan and W. Sadeddin, "Beneficiation of Calcareous Phosphate Rocks Using Dilute Acetic Acid Solutions: Optimisation of Operating Conditions for Ruseifa (Jordan) Phosphate," International Journal of Mineral Processing, Vol. 31, No. 1-2, 1991, pp. 115-126. http://dx.doi.org/10.1016/0301-7516(91)90008-7

[4] E. D. Economou, T. C. Vaimakis and E. M. Papmichael, "The Kinetics of Dissolution of the Carbonate Minerals Phosphate Ore Using Dilute Acetic Acid Solutions, the Case of PH Range from 3.96 to 6.40," Journal of Colloid and Interface Science, Vol. 245, No. 1, 2002, pp. 133-141. http://dx.doi.org/10.1006/jcis.2001.7931

[5] M. Ashraf, Z. I. Zafar and T. M. Ansari, "Selective Leaching Kinetics and Upgrading of Low-Grade Calcareous Phosphate Rock in Succinic Acid,” Hydrometallurgy, Vol. 80, No. 4, 2005, pp. 286-292. http://dx.doi.org/10.1016/j.hydromet.2005.09.001

[6] H. Sengul, A. K. Ozer and M. S. Gulaboglu, "Benefication of Mardin-Mazidagi (Turkey) Calcareous Phosphate Rock Using Dilute Acetic Acid Solutions,” International Journal of Mineral Processing, Vol. 30, 2006, pp. 113125.

[7] Z. I. Zafar and M. Ashraf, "Selective Leaching Kinetics of Calcareous Phosphate Rock in Lactic Acid,” The Canadian Journal of Chemical Engineering, Vol. 131, No. 1-3, 2007, pp. 41-48.

[8] E. M. E. Ouradi, "Etude de la Calcination du Phosphate Clair de Youssoufia (Maroc)," Afrique science Vol. 4, No. 2, 2008, pp. 199-211.

[9] F. Ben Brahim, A. Mgaidi and M. El Maaoui, "Exploration of Mesoporous Structure of Tunisian Raw and AcidLeached Phosphate Ore Particles," The Canadian Journal of Chemical Engineering, Vol. 75, No. 4, 1997, pp. 759764.

[10] A. Mgaidi, F. Ben Brahim, D. Oulahna, A. Nzihou and M. El Maaoui, "Chemical and Structural Changes of Raw Phosphate during Heat Treatment,” High temperature
Materails and Processes, Vol. 23, No. 3, 2004, p. 183.

[11] F. B. Brahim, "Dissolution des Phosphates Naturels dans l'Acide Phosphorique Dilué," Ph.D. Thesis, Faculty of Science of Tunis, University El Manar, Tunisia, 1999.

[12] P. Blazy and E.-A. Jdid, "Calcination du Phosphate Sédimentaire à Gangues Carbonatée en Four Rotatif d'Akashat (Irak) et en Four Eclair (flash)," Comptes Rendus de l'Académie des Sciences, Vol. 325, No. 10, 1997, pp. 761-764.

[13] M. Gharabaghi, M. Noaparast and M. Irannajad, "Selective Leaching Kinetics of Low-Grade Calcareous Phosphate Ore in Acetic Acid,” Hydrometallurgy, Vol. 95, No. 3-4, 2008, pp. 341-345

[14] E. O. Hoffmann, W. E. Cate, M. E. Demin and K. L. Elmore, "Rates of Solution of Calcium Phosphates Inn Phosphoric Acid Solutions,” Journal of Agricultural and Food Chemistry, Vol. 5, No. 4, 1957, pp. 266-275. http://dx.doi.org/10.1021/jf60074a001

[15] A. Yartasi, M. Kocakerim, S. Yapici and C. Ozmetin, "Dissolution Kinetics of Phosphate Ore in SO2-Saturated Water," Industrial \& Engineering Chemistry Research, Vol. 33, No. 9, 1994, pp. 2220-2225. http://dx.doi.org/10.1021/ie00033a028

[16] Y. Abali, S. Colak, A. Yartazi, "Dissolution Kinetics of Phosphate Rock with $\mathrm{Cl}_{2}$ Gas in Water," Hydrometallurgy, Vol. 46, No. 1-2, 1997, pp. 13-25. http://dx.doi.org/10.1016/S0304-386X(96)00094-1

[17] A. Brassens, “Mise en Evidence de Deux Types D'eau et de Deux Localisations des Ions $\mathrm{CO}_{3}{ }^{2-}$ dans la Matière Phosphatée d'un Phosphate Sedimentaire Marocain," Comptes Rendus de l'Académie des Sciences, 1975, p. 280.

[18] C. Szilas, C. B. Koch, M. M. Msolla and O. K. Broggard, "The Reactivity of Tanzanian Minjingu Phosphate Rock Can Be Assessed from the Chemical and Mineralogical Composition,” Geoderma1, Vol. 47, No. 3-4, 2008, pp. 172-177. http://dx.doi.org/10.1016/j.geoderma.2008.08.009 